\title{
Estudo laboratorial em bacias sanitárias de 4,8 L/descarga
}

\author{
Laboratory study in 4.8 liters per flush (Lpf) toilets
}

\section{Isabella Pastore Valêncio Orestes Marraccini Gonçalves}

\section{Resumo}

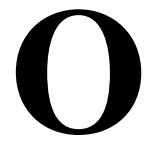

bjetivo da pesquisa apresentada neste artigo é verificar, laboratorialmente, a possibilidade de redução do volume consumido por descarga das bacias sanitárias em dois litros (de 6,8 para 4,8 L/descarga), ou seja, verificar se essa redução resulta em efeitos negativos no desempenho da bacia sanitária e do sistema predial de esgoto sanitário. Foram avaliadas vinte bacias sanitárias com caixa acoplada e acionamento simples de 4,8 L/descarga (tanto bacias sanitárias projetadas para funcionar com 4,8 $\mathrm{L} /$ descarga quanto bacias sanitárias projetadas para funcionar com 6,8 L/descarga, mas reguladas para 4,8 L/descarga). Foram realizados os ensaios previstos nas normas brasileiras NBR 15097 (bacias sanitárias) e NBR 15491 (caixas de descarga), ensaio de remoção de pasta de soja conforme norma norte americana ASME A112.19.2e ensaio de transporte de pasta de soja desenvolvido em entidade estrangeira (PlumbingEfficiencyResearchCoalition). Asbacias sanitárias atendem ao desempenho de remoção de dejetos da própria bacia, mas apenas cinco (25\%) foram aprovadas em todos os ensaios realizados, o que reflete a necessidade de melhoria no desenvolvimento das bacias sanitárias. No ensaio de transporte de pasta de soja, os resultados variaram de duas a seis descargas para fazer a limpeza da tubulação de dezoito metros de comprimento. Nenhuma das bacias sanitárias projetadas para funcionar com 6,8 L/descarga, mas reguladas para 4,8 L/descarga, foi aprovada nos ensaios laboratoriais, o que comprova que a simples redução do nível de água, na caixa de descarga, não é uma solução viável para reduzir o volume de água consumida pelas bacias sanitárias. O problema maior se dá com relação ao desempenho do sistema predial de esgoto sanitário. A redução do volume de descarga sem o estudo aprofundado do efeito gerado no sistema pode causar depósito de sólidos na tubulação.

Palavras-chave: Bacia sanitária. Sistemas hidráulicos e sanitários. Consumo de água.

\section{Abstract}

This study's objective is to investigate, in the laboratory, the flush volume reducing possibilityby two litres (from 6.8 to 4.8 Lpf), that is, to verify whether that reduction negatively impacts the performance of the toilet and drainage system. Twenty 4.8 Lpf toilets with flush tank and single flush were evaluated (toilets designed to operate with 4.8 Lpf and toilets designed to operate with 6.8 Lpf, but regulated to 4.8 Lpf). The tests were done according the Brazilian standards NBR 15097, for the toilets, and NBR 15491, for the flush tanks, the ASME A112.19.2 (waste extraction test) and Plumbing Efficiency Research Coalition study (soybean paste transport test). The toilets with flush tanks passed the solids removal test

1 Isabella Pastore Valêncio 1 Universidade de São Paulo São Paulo - SP - Brasil

2Orestes Marraccini Gonçalves 2Universidade de São Paulo São Paulo - SP - Brasil

Recebido em 18/07/17 Aceito em 09/11/17 from the toilet itself, but only five toilets (25\%) were approved in all laboratory tests, which reflects the need to improve the design of the toilets. In the soybean paste transport test, the results varied from two to six flushes to clean the eighteen meters-long pipe. None of the 6.8 Lpf toilets, but regulated to 4.8 Lpf, was approved in the laboratory tests, which proves that the simple reduction of the flush tank water level is not a viable solution to reduce flush volume. The biggest problem is related to the performance of the building's drainage system. Reducing flush volume without a deeper investigation of the effects generated in the system can cause deposit of solids in the piping.

Keywords: Toilet. Water supply and drainage systems. Water consumption. 


\section{Introdução}

Inicialmente, os esforços para aumentar a quantidade de água potável disponível para a população concentravam-se na gestão da oferta de água, por meio da captação em locais cada vez mais distantes e do aumento da extensão das redes de abastecimento. Entretanto, essas possibilidades tornaram-se cada vez mais difíceis, pois os recursos naturais foram se esgotando ou se tornando inviáveis, pela distância. Para contornar essas dificuldades enfrentadas pelos gestores, estudos da gestão de demanda passaram a ser valorizados (CONSELHO..., 2014). De acordo com Silva (2005), a gestão da demanda pode ser entendida como o acompanhamento constante do consumo de água, com controle de dados e informações que permitem a implantação de ações para manutenção e/ou melhoria dos indicadores de consumo.

No Brasil, na década de 1990, foram implementadas políticas públicas (programas permanentes), visando à redução do consumo de água (SILVA, 2005). Dentre as ações desenvolvidas pelos governos federal e estadual, destacam-se o Programa Nacional de Combate ao Desperdício de Água (PNCDA), o Programa de Uso Racional da Água (Pura), desenvolvido pela Companhia de Saneamento Básico do Estado de São Paulo (Sabesp), e o Programa Brasileiro da Qualidade e Produtividade do Habitat (PBQP-H), implementado pela Secretaria de Habitação do Ministério das Cidades.

Além dos programas permanentes existentes no Brasil, devido à crise hídrica de 2014, a Sabesp elaborou o Programa de Incentivo à Redução do Consumo, que se trata de descontos nas contas de água dos usuários que apresentarem redução de consumo, quando comparadas com a média dos meses anteriores. Entretanto, essas medidas dependem da participação ativa do usuário, e muitos apenas colaboram com essa redução apenas em períodos de estiagem (CONSELHO..., 2014).

Nesse sentido, as ações tecnológicas que promovem o uso eficiente da água, como, por exemplo, instalação de aparelhos sanitários economizadores de água, que não dependem de mudança no comportamento dos usuários, promovem redução permanente do consumo de água. Mudanças no comportamento ou nos hábitos dos usuários necessitam de uma mudança cultural para que sejam permanentes, pois, caso contrário, o efeito será temporário (durante um período de crise hídrica) (CÂMARA..., 2016).

Ainda com relação à instalação de aparelhos sanitários economizadores de água é importante ressaltar que para que a redução do consumo de água realmente ocorra, o aparelho deve atender aos requisitos mínimos de funcionamento. Por exemplo, caso uma bacia sanitária de volume reduzido provoque obstrução, o usuário terá que acionar duas (ou mais) vezes a descarga e a redução do consumo de água não acontecerá.

\section{Redução do consumo de água das bacias sanitárias e 0 transporte de sólidos ao longo da tubulação do sistema predial de esgoto sanitário}

Em 1997, com a finalidade de reduzir o consumo de água de edificações, o Ministério do Interior, por meio do Programa Brasileiro da Qualidade e Produtividade no Habitat (PBQP-H), estabeleceu em norma os novos limites máximos de utilização de água para a limpeza de bacias sanitárias, que deveriam ser adotados gradativamente até 2002 (OLIVEIRA, 2002). Assim, o consumo passaria de 12 L/descarga (admitido até 2002) para 6 L/descarga (após 2002). A norma atual do produto NBR 15097-1 (ABNT, 2017) estabelece o volume nominal de $6,8 \mathrm{~L} /$ descarga.

O consumo de água das bacias sanitárias reduziu significativamente ao longo dos anos; entretanto, de acordo com Valencio e Gonçalves (2017), esse consumo representa, em média, $19,4 \%$ do consumo de água total interno de uma residência. Esse valor foi calculado por meio de um estudo de campo em que o consumo de água de dez unidades habitacionais foi monitorado. Barreto (2008) obteve um valor próximo a esse em seu monitoramento, em que concluiu que a bacia sanitária representa $20,0 \%$ do consumo de água total interno de uma residência. Quando considerado o consumo de água total interno e externo, o consumo da bacia sanitária representa $5,5 \%$.

De acordo com Ghisi e Oliveira (2007), o consumo da bacia sanitária representa um dos maiores consumos de água de uma residência, perdendo apenas para o consumo de água do chuveiro. Em seu artigo, duas casas localizadas na cidade de Palhoça (Santa Catarina, Brasil) foram avaliadas. É possível verificar que em uma das casas avaliadas o consumo de água da bacia sanitária representa $30,4 \%$ do consumo total de água e, na outra, $25,6 \%$.

Motivada pela questão de redução do consumo de água e pelos impactos que isso pode causar no

446 Valêncio, I. P.; Gonçalves, O. M. 
sistema predial de esgoto sanitário, em 2012 a Plumbing Efficiency Research Coalition (PERC) publicou um estudo denominado The Drainline Tansport of Solid Waste in Buildings (PLUMBING..., 2012). Nesse estudo, a PERC verificou os efeitos da adoção de diferentes variáveis, dentre elas declividade da tubulação de esgoto predial de $1 \%$ e $2 \%$ e volumes de 3,0, 4,8 e $6,0 \mathrm{~L} /$ descarga. Esse estudo relatou problemas de entupimentos com descargas de $3,0 \mathrm{~L}$ e apontou que o desempenho das bacias de 6,0 L/descarga pode ser melhor do que as de 4,8 L/descarga para a limpeza total da tubulação do sistema predial de esgoto sanitário.

Nesse mesmo estudo foi possível verificar que uma bacia sanitária que utiliza um volume de descarga de 3,0 L/descarga necessita de pelo menos quatro vezes mais descargas para remover todas as mídias da tubulação do que uma bacia sanitária de 6,0 L/descarga. Isso indica que uma bacia sanitária com volume reduzido pode não ser econômica, uma vez que necessita de mais descargas para ter o mesmo desempenho da atualno que concerne à remoção de mídias da tubulação de esgoto sanitário. A Figura 1 mostra essas informações mais detalhadamente. Nessa figura, as barras com preenchimento em preto representam as descargas de 6,0 L, as barras em cinza escuroas descargas de $4,8 \mathrm{~L}$ e as barras em cinza claro as descargas de 3,0 L.

Comparando três barras do gráfico como exemplo (destacadas no gráfico da Figura 1), tem-se que todas as variáveis são as mesmas, com exceção do volume que é 6,0 L/descarga para a barra com preenchimento em preto; 3,0 L/descarga para a barra com preenchimento em cinza claro e 4,8 L/descarga para a barra com preenchimento em cinza escuro, respectivamente. Nota-se que para o volume de 3,0 L foram necessárias 26 descargas para remover as mídias, enquanto para os volumes de 6,0 L e 4,8 L foram necessárias em média oito e doze descargas, respectivamente. Portanto, para a bacia sanitária de 3,0 L/descarga foram utilizados $78,0 \mathrm{~L}$ para limpeza da tubulação, e para as bacias de 6,0 e 4,8 L/descarga foram utilizados $48,0 \mathrm{~L}$ e $57,6 \mathrm{~L}$, respectivamente.

Outra diferença indicada nesse estudo é o impacto da declividade do ramal de esgoto. Uma bacia sanitária pode precisar de até o dobro de descargas para remover as mídias do ramal de esgoto quando as declividades variam de $2 \%$ para $1 \%$

Figura 1 - Gráfico que indica a média de descargas necessárias para remover todas as mídias do tubo de esgoto para diferentes condições de ensaio

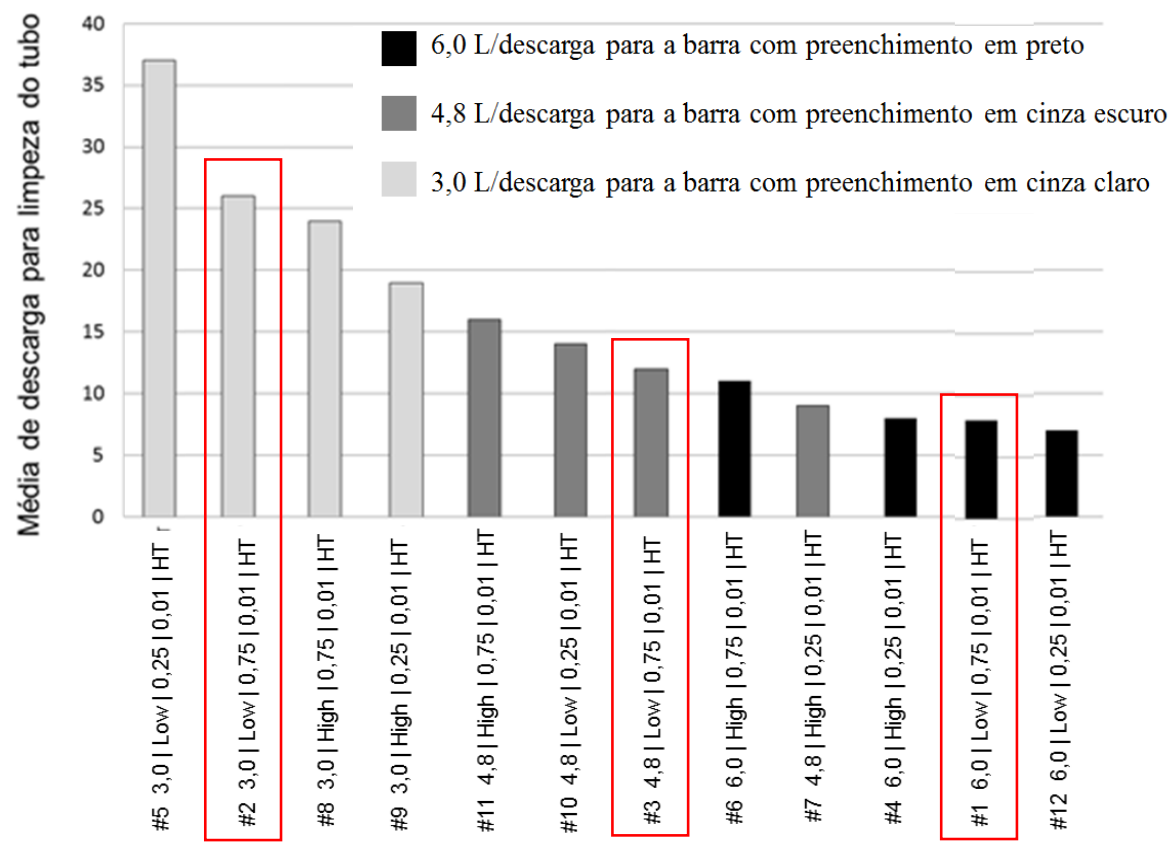

Fonte: adaptado de PERC (PLUMBING..., 2012).

Nota: Legenda: eixo das abscissas:

$1^{\text {a }}$ variável - \# 1; \# 2; ...; \# 12 - Número da amostra ensaiada;

$2^{a}$ variável - 3,0; 4,8; 6,0 - Volume consumido por descarga;

$3^{a}$ variável - Low; High - Taxa de descarga;

$4^{\mathrm{a}}$ variável - 0,75; 0,25 - Porcentagem de água no injetor;

$5^{a}$ variável - 0,01 - Declividade do ramal de descarga; e

$6^{\text {a }}$ variável - HT - Modelo do papel higiênico utilizado como mídia - high tensile - folha dulpa. 
A fase 2 do estudo da PERC (PLUMBING..., 2015) analisa os efeitos de duas variáveis: volume de descarga de 3,8 L e seção transversal da tubulação de esgoto com diâmetro de $75 \mathrm{~mm}$. Os resultados mostraram que a redução do volume de descarga de 4,8 L para $3,8 \mathrm{~L}$ faz com que o desempenho do sistema decaia consideravelmente para a declividade de $1 \%$ da tubulação. Com relação à seção transversal da tubulação, a redução do diâmetro de $100 \mathrm{~mm}$ para $75 \mathrm{~mm}$ não indicou melhoria no desempenho do sistema (Figura 2).

No Japão, desde 2011 são utilizadas bacias sanitárias de 4,0 L/descarga (KOBAYASHI, OTSUKA, 2012). De acordo com os autores, hoje já estão disponíveis bacias sanitárias ainda mais econômicas, com volume de 3,8 L/descarga. Entretanto, destacam que a diminuição do volume pode acarretar em problemas no transporte das mídias.

Gauley e Koeller (2005) afirmam que a distância percorrida pelos dejetos aumenta diretamente com o aumento da declividade da tubulação de esgoto sanitário, conforme detalhado na Figura 3.

\section{Objetivo}

O objetivo da pesquisa apresentada neste artigo é verificar, laboratorialmente, a possibilidade de redução do volume consumido por descarga das bacias sanitárias em dois litros (de 6,8 L/descarga para 4,8 L/descarga), ou seja, verificar se essa redução resulta em efeitos negativos no que diz respeito ao desempenho da bacia sanitária e do sistema predial de esgoto sanitário.

Figura 2 - Médias de descarga para limpeza da tubulação

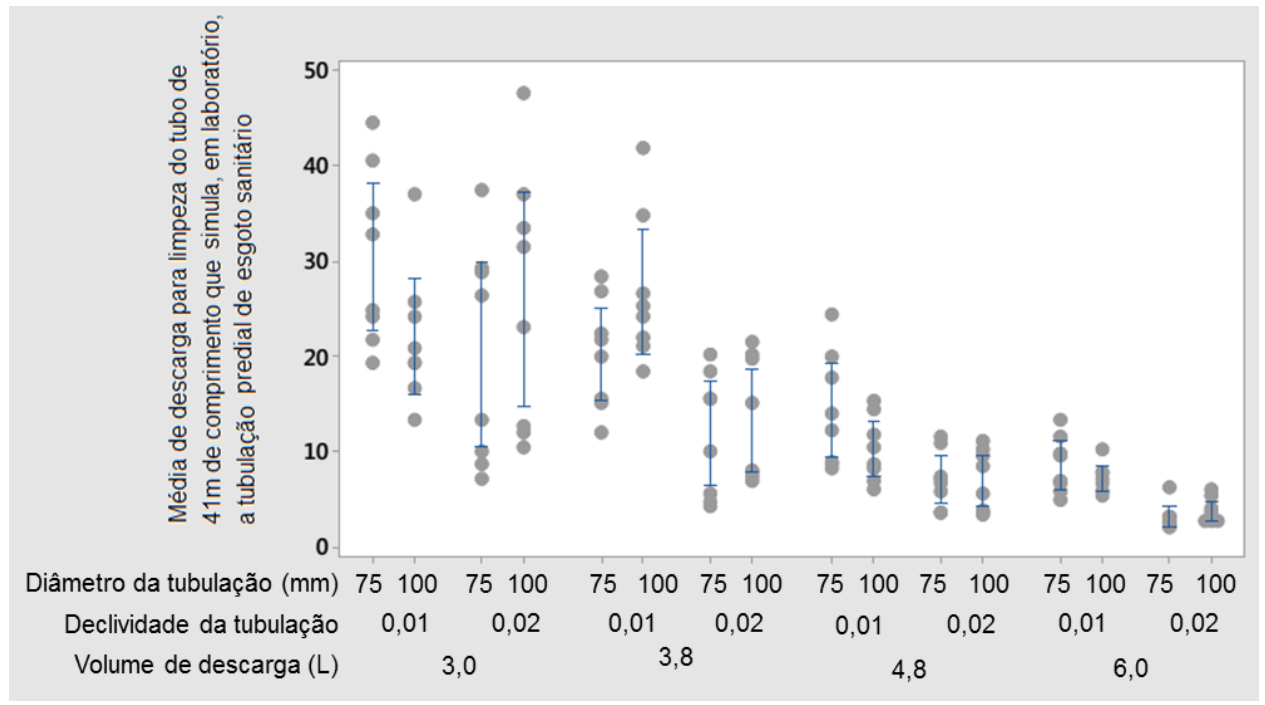

Fonte: adaptado de PERC (PLUMBING..., 2015).

Figura 3 - Diferença entre declividade do ramal de esgoto para tubulação de diâmetro de $75 \mathrm{~mm}$



Fonte: adaptado de Gauley e Koeller (2005).

448 Valêncio, I. P.; Gonçalves, O. M. 


\section{Método}

A metodologia apresentada baseia-se na execução de ensaios em conformidade com as normas de referência (detalhadas no Quadro 1) para bacias sanitárias com caixa acoplada, visando à determinação do desempenho destas.

Os ensaios de verificação do desempenho das bacias sanitárias da norma brasileira NBR 15097-1 (ABNT, 2017) foram baseados na norma americana ASME A112.19.2, publicada em 2003. Em 2013, a norma ASME A112.19.2 foi revisada para abranger bacias sanitárias de 4,8 e 6,8 L/descarga. Nessa revisão, foi acrescido o ensaio de remoção de pasta de soja para caracterizar as bacias sanitárias de 4,8 L/descarga. Antes disso, era um ensaio previsto pelo sistema de certificação Water Sense da Environmental Protection Agency (EPA) para certificar bacias sanitárias. Nesse estudo, optou-se pela realização de todos os ensaios de desempenho previstos nas normas brasileiras, acrescidos pelo ensaio de remoção de pasta de soja.

Os ensaios que avaliam o desempenho das bacias sanitárias são projetados para verificar se o produto atende às seguintes funções desejadas pelos usuários e pelo sistema:

(a) os ensaios de remoção das diversas mídias (esferas, grânulos e mídia composta) são realizados para verificar a capacidade de remoção os dejetos da própria bacia sanitária. Caso o produto não atenda a algum desses requisitos é possível que, em campo, a bacia sanitária apresente entupimentos;

(b) com o ensaio de transporte de sólidos verificase se a descarga da bacia sanitária tem energia suficiente para transportar os dejetos ao longo do condutor horizontal, para evitar possíveis entupimentos na rede de esgoto;

(c) no ensaio de lavagem de parede verifica-se se o escoamento da descarga faz a limpeza adequada do interior da bacia sanitária, pois a falta de limpeza da bacia sanitária pode ocasionar risco à saúde do usuário (pela contaminação) e mau cheiro;

(d) no ensaio de reposição do fecho hídrico verifica-se a autossifonagem da bacia sanitária a fim de evitar o retorno de gases do sistema de esgoto ao ambiente sanitário; e

(e) com o ensaio de respingos de água verifica-se se a água do poço da bacia sanitária respinga para fora da bacia durante o funcionamento da descarga. O problema do não atendimento desse requisito é a possibilidade de risco à saúde do usuário ocasionado pelo contato com a água com dejetos.

Além dos ensaios de desempenho da bacia sanitária, foram realizados também ensaios para avaliar o desempenho da caixa de descarga. Estes estão ligados ao consumo de água, segurança e conforto do usuário, conforme descrito a seguir:

(a) os ensaios de estanqueidade da torneira de boia e estanqueidade da caixa de descarga são realizados para verificar se o produto não apresenta vazamentos;

(b) os ensaios de tempo de enchimento e esforço de acionamento são requisitos ligados ao conforto do usuário, pois uma caixa de descarga com um tempo de enchimento alto ou que necessite de um grande esforço para acionamento da descarga pode causar desconforto ao usuário;

(c) o requisito de capacidade do extravasor está relacionado ao consumo de água, pois verifica-se se, em caso de avarias nos mecanismos internos da caixa de descarga, ou seja, se o nível de água da caixa de descarga não parar de subir automaticamente, a água terá espaço suficiente para não transbordar para fora da caixa de descarga;

(d) os ensaios de resistência ao uso, estanqueidade da boia e resistência do mecanismo de acionamento são realizados para avaliar a durabilidade da caixa de descarga, ou seja, a capacidade de o produto resistir ao uso; e

(e) o ensaio de resistência à carga estática está relacionado à segurança do usuário e é realizado para verificar se a caixa de descarga não apresentará trincas ou outra avaria ao ser pressionada, simulando um usuário apoiado na caixa de descarga.

A bancada de ensaios onde a bacia sanitária foi instalada para a realização dos ensaios simula a condição real de instalação em uma edificação e foi construída conforme a norma brasileira NBR 15097-1 (ABNT, 2017). Para simular o ramal de esgoto predial, a bancada de ensaios possui um tubo de $18 \mathrm{~m}$ de comprimento com declividade de $1 \%$ e diâmetro de $100 \mathrm{~mm}$ que pode ser acoplado à saída da bacia sanitária. A Figura 4 apresenta um esquema da bancada de ensaios e a Figura 5 uma foto de uma bacia sanitária instalada na bancada de ensaios. 
Quadro 1 - Ensaios realizados e documentos de referência

\begin{tabular}{|l|l|}
\hline \multicolumn{1}{|c|}{ Documento de referência } & \multicolumn{1}{c|}{ Ensaios realizados } \\
\hline $\begin{array}{l}\text { NBR 15097-1 (ABNT, 2017): } \\
\text { aparelhos sanitários de material } \\
\text { cerâmico: Requisitos e métodos de } \\
\text { ensaio }\end{array}$ & $\begin{array}{l}\text { Volume de água consumido por descarga; Respingos de água; } \\
\text { Reposição do fecho hídrico; Lavagem de parede; Remoção de } \\
\text { grânulos; Remoção de mídia composta; Remoção de esferas; } \\
\text { Transporte de sólidos. }\end{array}$ \\
\hline $\begin{array}{l}\text { NBR 15491 (ABNT, 2010): caixa de } \\
\text { descarga para limpeza de bacias } \\
\text { sanitárias:requisitos e métodos de } \\
\text { ensaio }\end{array}$ & $\begin{array}{l}\text { Tempo de enchimento; Capacidade do extravasor; Estanqueidade } \\
\text { da torneira de boia; Estanqueidade da caixa de descarga; } \\
\text { Estanqueidade da boia; Esforço de acionamento; Resistência ao } \\
\text { mecanismo de acionamento; Resistência ao uso; Resistência à } \\
\text { carga estática. }\end{array}$ \\
\hline $\begin{array}{l}\text { ASME A112.19.2 (AMERICAN..., } \\
\text { 2013): ceramic plumbing fixtures }\end{array}$ & Remoção de pasta de soja \\
\hline $\begin{array}{l}\text { The Drainline Transport of Solid } \\
\text { Waste in Buildings (PLUMBING..., } \\
\text { 2012) }\end{array}$ & Transporte de sólidos deformáveis \\
\hline
\end{tabular}

Figura 4 - Esquema da bancada de ensaios

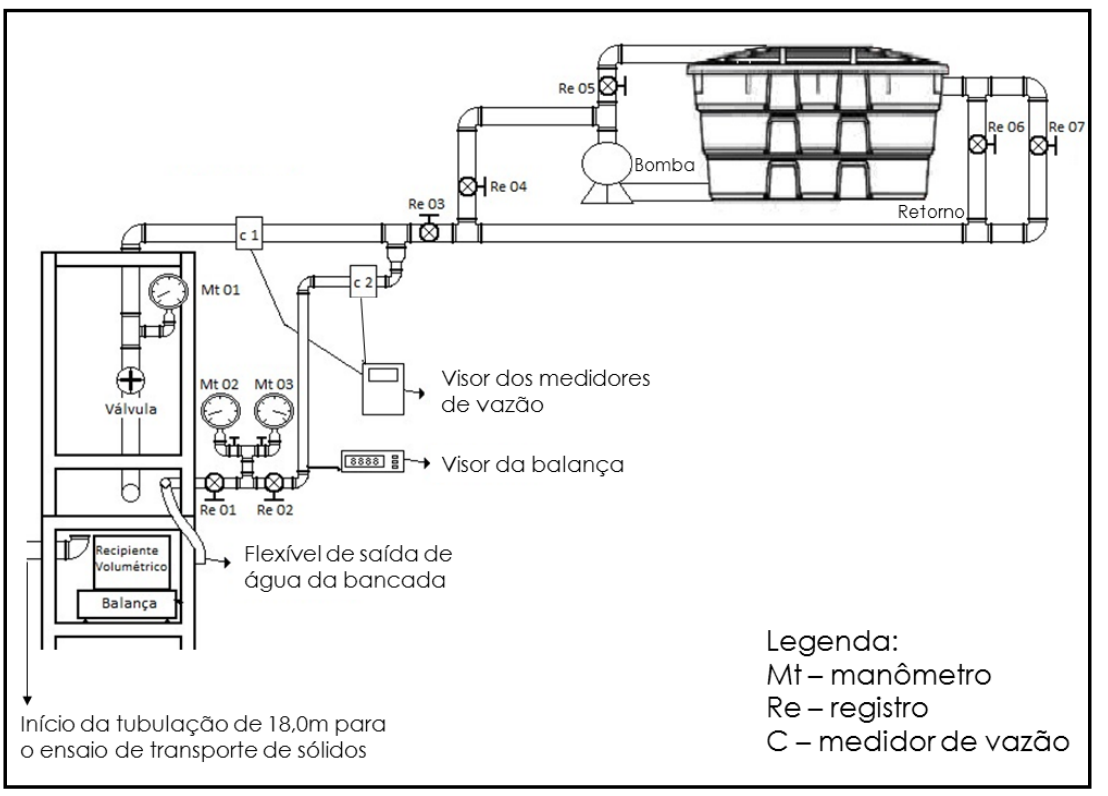

Figura 5 - Foto do local para instalação da bacia sanitária na bancada de ensaios

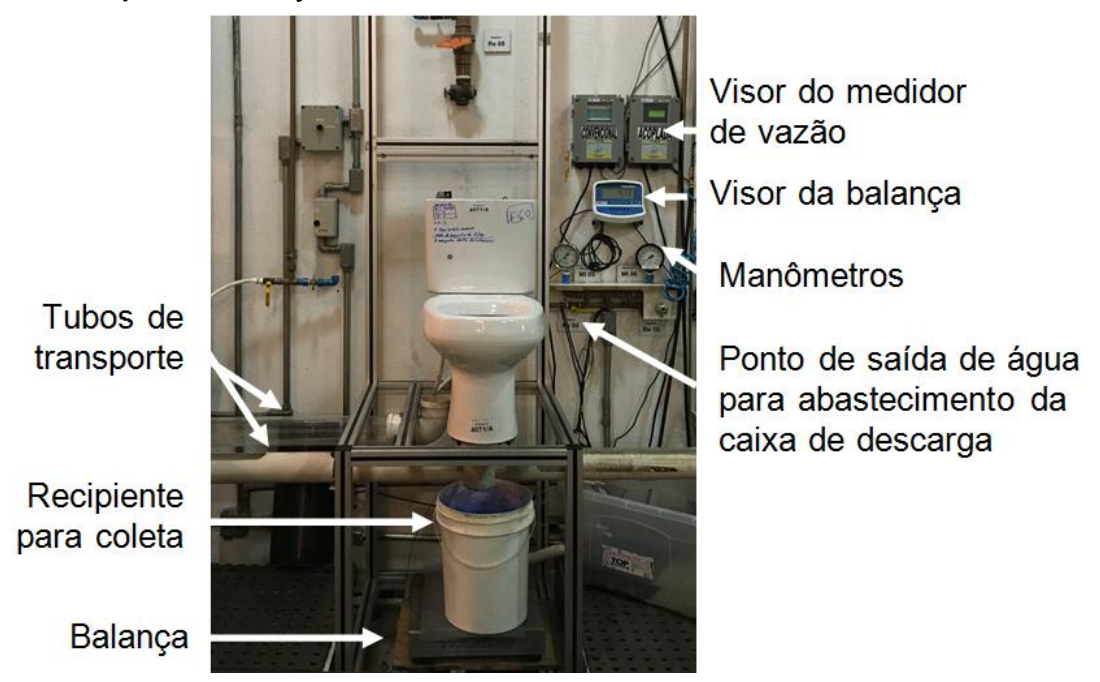

450 Valêncio, I. P.; Gonçalves, O. M. 
Quadro 2 - Requisitos avaliados (Continua...)

\begin{tabular}{|c|c|c|}
\hline $\begin{array}{l}\text { Norma de } \\
\text { referência }\end{array}$ & Requisitos & Métodos de ensaio evalores especificados \\
\hline \multirow{8}{*}{ 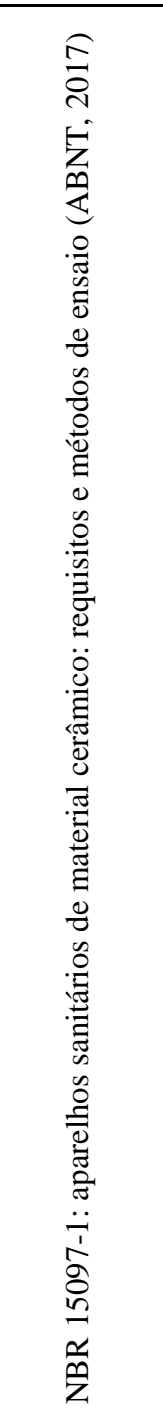 } & $\begin{array}{l}\text { Volume de água } \\
\text { consumido por } \\
\text { descarga }^{1}\end{array}$ & $\begin{array}{l}\text { As bacias sanitárias com caixa acoplada devem apresentar volume de água } \\
\text { consumido por descarga, em alta e baixa pressão ( } 400 \mathrm{kPa} \text { e } 30 \mathrm{kPa} \text {, } \\
\text { respectivamente), igual a } 4,8 \mathrm{~L} \text {, com variação de } \pm 0,4 \text {. O resultado do } \\
\text { ensaio é a média aritmética de três repetições. }\end{array}$ \\
\hline & $\begin{array}{l}\text { Remoção de } \\
\text { mídia composta }\end{array}$ & $\begin{array}{l}\text { Após acionar o aparelho de descarga com vinte esponjas de poliuretano e } \\
\text { oito folhas de papel tipo kraft no poço da bacia, o número de mídias } \\
\text { removidas na primeira descarga deve ser, no mínimo, 22. O resultado do } \\
\text { ensaio é a média aritmética de três repetições. As mídias que não forem } \\
\text { removidas na primeira descarga devem ser totalmente removidas na } \\
\text { segunda descarga em todas as repetições. }\end{array}$ \\
\hline & $\begin{array}{l}\text { Remoção de } \\
\text { esferas }\end{array}$ & $\begin{array}{l}\text { Após acionar o aparelho de descarga com } 100 \text { esferas de polipropileno no } \\
\text { poço da bacia sanitária, a média do número de esferas removidas da bacia } \\
\text { depois das descargas deve ser, no mínimo, } 80 \text {. O resultado do ensaio é a } \\
\text { média aritmética de três repetições. }\end{array}$ \\
\hline & $\begin{array}{l}\text { Lavagem de } \\
\text { parede }\end{array}$ & $\begin{array}{l}\text { Traçar uma linha ao longo de todo o perímetro da bacia sanitária a } 25 \mathrm{~mm} \\
\text { abaixo dos pontos de saída de água. Após a descarga: } \\
\text { a) a média da soma dos comprimentos dos segmentos de linha de tinta } \\
\text { remanescentes deve ser de, no máximo, } 50 \mathrm{~mm} \text {. O resultado do ensaio é a } \\
\text { média aritmética de três repetições. } \\
\text { b) nenhum segmento remanescente deve ser maior que } 13 \mathrm{~mm} \text { em nenhuma } \\
\text { repetição. }\end{array}$ \\
\hline & $\begin{array}{l}\text { Remoção de } \\
\text { grânulos }\end{array}$ & $\begin{array}{l}\text { Adicionando-se } 100 \mathrm{~cm}^{3} \text { de polietileno de alta densidade e } 100 \text { esferas de } \\
\text { nylon, na bacia, a média dos grânulos visíveis no poço da bacia após a } \\
\text { descarga deve ser de, no máximo, 125. E a média de esferas de nylon } \\
\text { visíveis no poço não deve ser superior a cinco. O resultado do ensaio é a } \\
\text { média aritmética de três repetições. }\end{array}$ \\
\hline & $\begin{array}{l}\text { Respingos de } \\
\text { água }\end{array}$ & $\begin{array}{l}\text { Após as descargas, a média do número de respingos com diâmetro (ou outra } \\
\text { dimensão preponderante) igual ou maior que } 5 \mathrm{~mm} \text { acima do plano de } \\
\text { transbordamento da bacia deve ser de, no máximo, oito respingos. O } \\
\text { resultado do ensaio é a média aritmética de três repetições. }\end{array}$ \\
\hline & $\begin{array}{l}\text { Reposição do } \\
\text { fecho hídrico }\end{array}$ & $\begin{array}{l}\text { Após cada descarga, a bacia sanitária deve apresentar reposição do fecho } \\
\text { hídrico feito pelo dispositivo provedor de água, de modo que sua altura seja } \\
\text { sempre maior ou igual a } 50 \mathrm{~mm} \text {. O resultado é o menor valor de altura do } \\
\text { fecho hídrico obtido em três repetições. }\end{array}$ \\
\hline & $\begin{array}{l}\text { Transporte de } \\
\text { sólidos }\end{array}$ & $\begin{array}{l}\text { A distância média percorrida por esfera, ao longo do ramal de descarga, } \\
\text { deve ser igual ou maior que } 10 \mathrm{~m} \text {. O resultado do ensaio é a média } \\
\text { aritmética de três repetições. }\end{array}$ \\
\hline \multirow{4}{*}{ 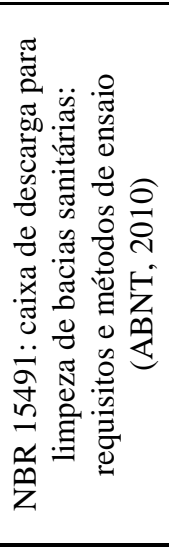 } & $\begin{array}{l}\text { Resistência ao } \\
\text { uso }\end{array}$ & $\begin{array}{l}\text { A caixa de descarga, após ser submetida a } 15.000 \text { ciclos de funcionamento, } \\
\text { não deve apresentar quebra ou dano. }\end{array}$ \\
\hline & $\begin{array}{l}\text { Resistência à } \\
\text { carga estática }\end{array}$ & $\begin{array}{l}\text { A caixa de descarga deve resistir a um esforço de compressão de } 100 \mathrm{~N} \text {, } \\
\text { aplicado durante } 300 \mathrm{~s} \text {, através de um disco de } 150 \mathrm{~mm} \text { de diâmetro, na } \\
\text { região frontal e central do corpo da caixa, sem que ocorram fraturas ou } \\
\text { deteriorações que impeçam seu funcionamento normal ou alterem o seu } \\
\text { aspecto exterior. }\end{array}$ \\
\hline & $\begin{array}{l}\text { Tempo de } \\
\text { enchimento }\end{array}$ & $\begin{array}{l}\text { O tempo necessário para abastecer a caixa de descarga até o volume útil } \\
\text { menos } 200 \mathrm{~mL} \text { de água deve ser de, no máximo, } 240 \text { segundos. O resultado } \\
\text { do ensaio é a média aritmética de três repetições. }\end{array}$ \\
\hline & $\begin{array}{l}\text { Capacidade do } \\
\text { extravasor }\end{array}$ & $\begin{array}{l}\text { A distância entre o nível da água no interior da caixa de descarga e o nível } \\
\text { de afogamento do dispositivo antirretorno da torneira de boia (ou da } \\
\text { extremidade da saída de água dessa torneira) deve ser de, no mínimo, cinco } \\
\text { milímetros. }\end{array}$ \\
\hline
\end{tabular}

${ }^{1}$ Por se tratar de um estudo para avaliar a possibilidade de reduzir o volume de descarga, foi adotado o limite de 4,8 $\pm 0,4 \mathrm{~L}$. 0 limite atual da norma para bacias sanitárias com caixa acoplada é de 5,8 L a 7,1 L. 
Quadro 2 - Requisitos avaliados (continuação)

\begin{tabular}{|c|c|c|}
\hline $\begin{array}{l}\text { Norma de } \\
\text { referência }\end{array}$ & Requisitos & Métodos de ensaio evalores especificados \\
\hline \multirow{5}{*}{ 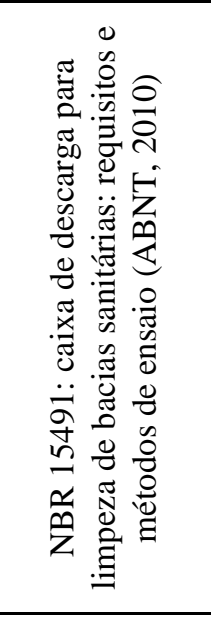 } & $\begin{array}{l}\text { Estanqueidade da } \\
\text { torneira de boia }\end{array}$ & $\begin{array}{l}\text { A torneira de boia deve ser estanque quando submetida à pressão } \\
\text { hidrostática de } 24 \mathrm{kPa} \text { e } 600 \mathrm{kPa} \text { para caixas de descarga acopladas e/ou } \\
\text { integradas. }\end{array}$ \\
\hline & $\begin{array}{l}\text { Estanqueidade da } \\
\text { caixa de descarga }\end{array}$ & $\begin{array}{l}\text { A caixa de descarga não deve apresentar vazamento pelo obturador do } \\
\text { mecanismo de descarga, não deve vazar por qualquer parte do corpo ou, no } \\
\text { caso de material que absorva água, permitir a formação de gotas por } \\
\text { exsudação. }\end{array}$ \\
\hline & $\begin{array}{l}\text { Esforço de } \\
\text { acionamento }\end{array}$ & $\begin{array}{l}\text { O esforço de acionamento necessário para acionar a caixa e iniciar a } \\
\text { descarga deve ser de, no máximo, } 30 \text { N ou } 1 \text { N.m. O resultado do ensaio é } \\
\text { a média aritmética de três repetições. }\end{array}$ \\
\hline & $\begin{array}{l}\text { Resistência do } \\
\text { mecanismo de } \\
\text { acionamento }\end{array}$ & $\begin{array}{l}\text { O mecanismo de acionamento deve resistir a um esforço cinco vezes maior } \\
\text { do que o esforço necessário para acionar a caixa. }\end{array}$ \\
\hline & $\begin{array}{l}\text { Estanqueidade da } \\
\text { boia }\end{array}$ & $\begin{array}{l}\text { A boia oca não deve permitir a penetração de água em seu interior. } \\
\text { Esse requisito não se aplica a outros tipos de boia. }\end{array}$ \\
\hline 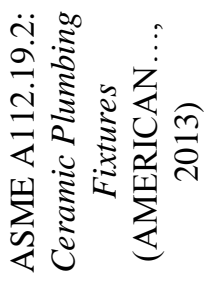 & $\begin{array}{l}\text { Remoção de pasta } \\
\text { de soja não } \\
\text { encapsulada }\end{array}$ & $\begin{array}{l}\text { Após acionar o aparelho de descarga com sete mídias de pasta de soja não } \\
\text { encapsuladas (de } 50 \mathrm{~g} \text { cada) e quatro bolas de papel (formadas por seis } \\
\text { pedaços de papel cada uma) no poço da bacia sanitária, todas as mídias } \\
\text { devem ser removidas e o fecho hídrico deve ser reposto em quatro das } \\
\text { cinco repetições realizadas. }\end{array}$ \\
\hline 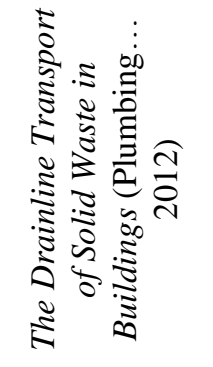 & $\begin{array}{l}\text { Transporte de } \\
\text { sólidos } \\
\text { deformáveis }\end{array}$ & $\begin{array}{l}\text { Acionar o aparelho de descarga com sete mídias de pasta de soja (de } 50 \mathrm{~g} \\
\text { cada) e quatro bolas de papel (formadas por seis pedaços de papel cada } \\
\text { uma) no poço da bacia sanitária e verificar a distância percorrida pelas } \\
\text { mídias em cada descarga sucessiva. } \\
\text { Este ensaio foi realizado com as mídias encapsuladas e não encapsuladas, } \\
\text { para fins de comparação. Por se tratar de uma avaliação prospectiva, não } \\
\text { foi considerado para a aprovação ou reprovação das bacias sanitárias. }\end{array}$ \\
\hline
\end{tabular}

Figura 6 - Fotos das mídias de ensaio utilizadas nos ensaios de remoção de esferas, transporte de sólidos, remoção de grânulos e remoção de mídia composta

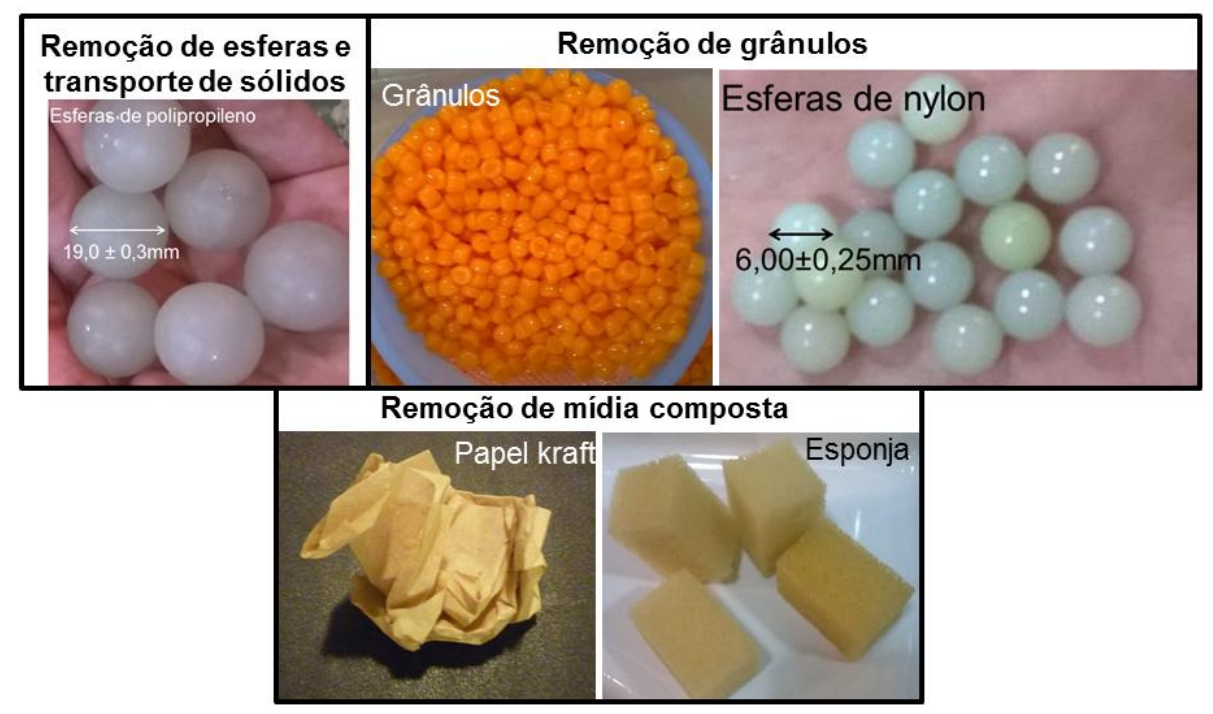

452 Valêncio, I. P.; Gonçalves, O. M. 
O ensaio de volume consumido por descarga foi realizado para confirmar que as bacias sanitárias utilizam em torno de $4,8 \pm 0,4 \mathrm{~L} /$ descarga e os demais ensaios foram realizados com o método de ensaio dos documentos de referência, porém considerando que as bacias sanitárias estavam reguladas para o volume de $4,8 \mathrm{~L} /$ descarga. O Quadro 2 apresenta detalhamento dos requisitos avaliados, e a Figura 6 fotos das mídias de ensaio.

Os ensaios foram realizados de acordo com um fluxograma (Figura 7), e, assim que constatada uma reprovação, os demais ensaios eram paralisados.

No total, foram ensaiados vinte modelos de bacias sanitárias, com caixa acoplada e acionamento simples de 4,8 L/descarga e 6,8 L/descarga (reguladas para funcionamento com 4,8 L/descarga), de fabricantes diferentes, tanto nacionais quanto internacionais. A Tabela 1 apresenta a codificação das bacias sanitárias por fabricante. Nota-se que alguns fabricantes possuem mais de uma bacia sanitária ensaiada, mas cada codificação representa um modelo de bacia sanitária diferente.

Dentre as bacias sanitárias ensaiadas, havia bacias sanitárias projetadas para funcionar com 4,8 L/descarga (90\% das amostras avaliadas) e bacias sanitárias de 6,8 L/descarga, atualmente vendidas no mercado, mas reguladas para $4,8 \mathrm{~L} /$ descarga (10\% das amostras avaliadas). Nessas últimas, foi feita uma regulagem da caixa de descarga para que ela fornecesse o volume de 4,8 L/descarga.

Os resultados dos ensaios realizados, bem como a discussão desses resultados, são apresentados na seção seguinte deste artigo.

\section{Resultados e discussão}

Como pode ser visto na Figura 8, todas as bacias sanitárias avaliadas, tanto com a pressão de abastecimento de água de $30 \mathrm{kPa}$ quanto de 400 $\mathrm{kPa}$, apresentaram volume de 4,8 $\pm 0,4 \mathrm{~L} /$ descarga.

Figura 7 - Fluxograma de realização dos ensaios

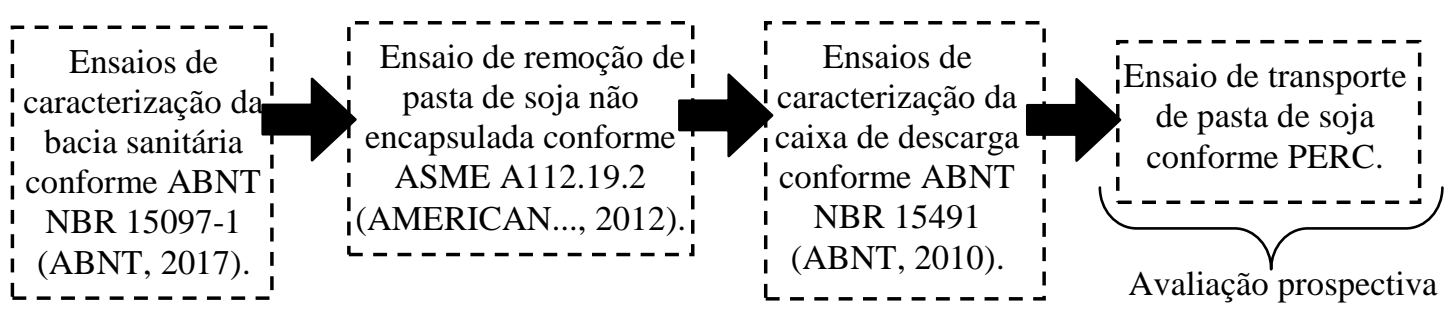

Tabela 1- Codificação das amostras avaliadas

\begin{tabular}{c|c}
\hline Empresa & $\begin{array}{c}\text { Codificação das bacias } \\
\text { sanitárias }\end{array}$ \\
\hline Fabricante 1 & 1 \\
& 2 \\
& 3 \\
Fabricante 2 & 4 \\
\hline Fabricante 3 & 5 \\
\hline \multirow{2}{*}{ Fabricante 4 } & 6 \\
\hline Fabricante 5 & 7 \\
\hline & 8 \\
& 10 \\
\hline Fabricante 6 & $11^{*}$ \\
& 12 \\
\hline \multirow{2}{*}{ Fabricante 7 } & $13^{*}$ \\
& 14 \\
& 15 \\
& 16 \\
\end{tabular}

Nota: *bacias sanitárias de 6,8 L/descarga, reguladas para 4,8 L/descarga. 
Figura 8 - Resultado do ensaio de volume consumido por descarga

Volume consumido por descarga em $30 \mathrm{kPa}$

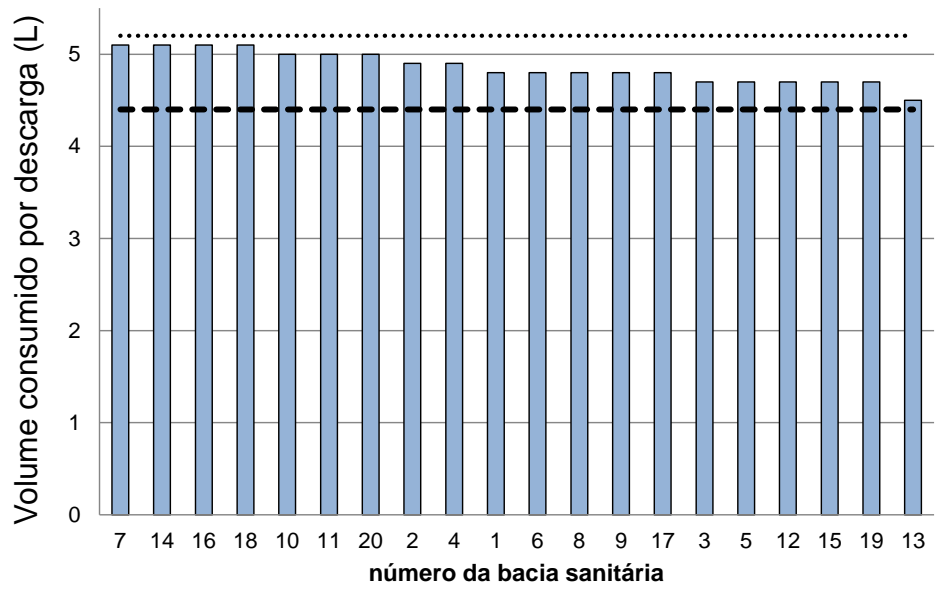

Volume consumido por descarga em $400 \mathrm{kPa}$



Com relação aos ensaios que verificam a remoção dos dejetos da própria bacia sanitária (remoção de esferas, remoção de mídia composta e remoção de grânulos), 19 bacias sanitárias $(95 \%)$ foram aprovadas. Somente uma bacia sanitária foi reprovada no ensaio de remoção de mídia composta (bacia sanitária n. 1) por não remover todas as mídias remanescentes na segunda descarga.

Uma bacia sanitária (5\%) não fez a reposição do fecho hídrico (bacia sanitária n. 11), apresentando valor da altura do fecho hídrico após a descarga $24 \%$ menor do que o mínimo necessário para que não haja o retorno de odores para dentro da residência. Assim, foi considerada reprovada nesse requisito.

Uma bacia sanitária (5\%) não fez a lavagem de parede adequada e foi reprovada nesse ensaio (bacia sanitária n. 5), com o maior segmento remanescente $230 \%$ maior do que o permitido em norma.

Quatro bacias sanitárias foram reprovadas no ensaio de transporte de sólidos (bacias sanitárias n. 13, 15, 16 e 19). As bacias sanitárias reprovadas nesse ensaio não fornecem a energia suficiente para transportar as esferas, ao longo do ramal de descarga, pela distância mínima exigida em norma (10 metros a partir da saída da bacia sanitária), o que é um indicativo de que o maior problema encontrado na redução do volume de descarga pode estar na remoção dos sólidos do sistema predial de esgoto sanitário. A Figura 9 apresenta o resultado do ensaio por bacia sanitária.

$\mathrm{O}$ não atendimento nos requisitos estabelecidos na norma brasileira atual NBR 15097-1 (ABNT, 2017) em $35 \%$ das bacias sanitárias avaliadas mostra a necessidade de melhoria no desenvolvimento das bacias sanitárias com caixa acoplada de 4,8 L/descarga. 
Figura 9 - Resultado do ensaio de transporte de sólidos

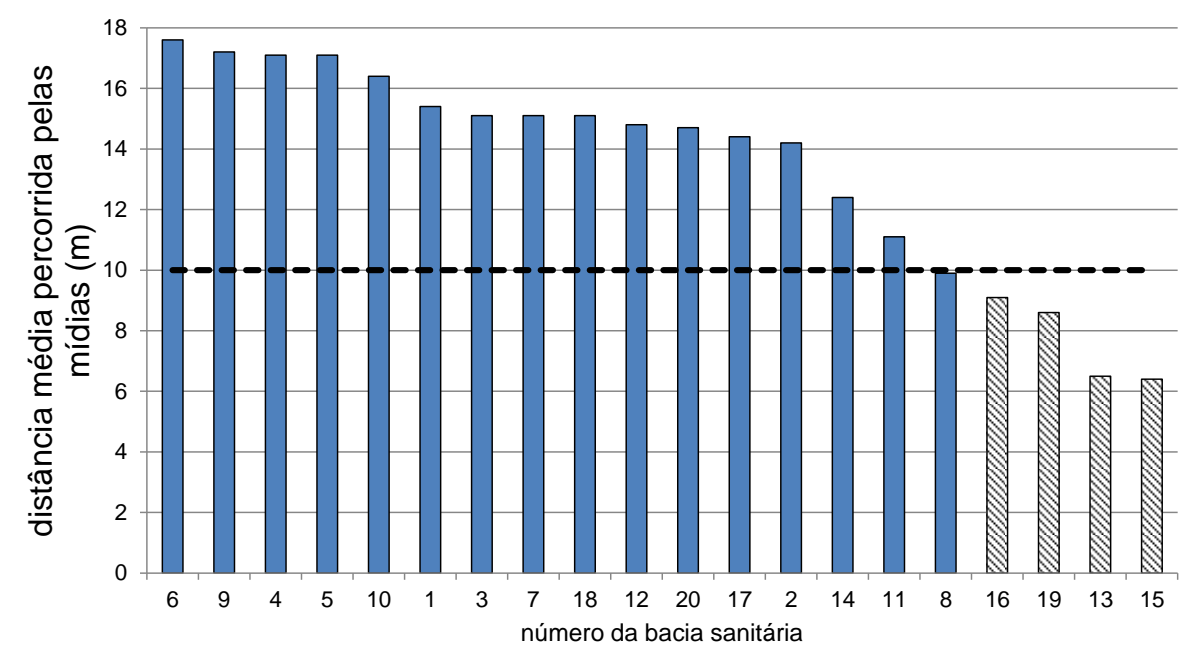

$\mathrm{Na}$ etapa seguinte (remoção de pasta de soja), foram ensaiadas treze das vinte amostras iniciais (apenas as aprovadas). Destas, cinco foram consideradas aprovadas de acordo com a ASME A112.19.2 (AMERICAN..., 2013) - bacias sanitárias n. 6, 10, 17, 18 e 20, cinco foram reprovadas com valores bem abaixo do limite normativo - bacias sanitárias n. 2, 3, 7, 8 e 14, e outras três foram reprovadas, mas com um resultado próximo do limite normativo (bacias sanitárias n. 4, 9 e 12). Então, para fins de estudo, continuaram-se os ensaios nessas bacias sanitárias. A Figura 10 mostra uma foto das mídias utilizadas por descarga nesse ensaio.

O ensaio de remoção de pasta de soja é um ensaio mais crítico do que os demais ensaios de remoção realizados e ainda não está previsto na norma brasileira. Entretanto, já é um ensaio comumente realizado nos Estados Unidos e na Europa. Das amostras avaliadas nesse requisito, $62 \%$ foram reprovadas.

$\mathrm{Na}$ etapa seguinte foram realizados os ensaios de desempenho da caixa de descarga em oito bacias sanitárias com caixa de descarga (aquelas aprovadas e com resultado próximo ao limite). Uma amostra foi reprovada no requisito de estanqueidade da caixa de descarga (bacia sanitária com caixa acoplada n. 12). O não atendimento desse requisito pode acarretar para os usuários a utilização de um volume de água desnecessário. Nesses casos, a água da caixa de descarga pode escorrer para dentro da bacia sanitária, sendo, muitas vezes, imperceptível para o usuário.

Assim, cinco bacias sanitárias foram consideradas aprovadas em todos os ensaios laboratoriais realizados, que representa apenas $25 \%$ das bacias sanitárias avaliadas. Nota-se a dificuldade dos produtos em atender os requisitos normativos vigentes.

Foram ensaiadas tanto bacias sanitárias projetadas para funcionar com 4,8 L/descarga (bacias sanitárias n. 1 a 10,12, 14 a 20) quanto bacias sanitárias projetadas para funcionar com 6,8 L/descarga, mas reguladas para 4,8 L/descarga (bacias sanitárias n. 11 e 13). Dessas últimas, nenhuma foi aprovada nos ensaios laboratoriais. A bacia sanitária n. 11 foi reprovada no ensaio de reposição do fecho hídrico e a bacia sanitária n. 13 foi reprovada no ensaio de transporte de sólidos. Ambas, quando ensaiadas com o volume de 6,8 L/descarga, foram aprovadas, o que comprova que a simples redução do nível de água na caixa de descarga não é uma solução viável para reduzir o volume de água consumido pelas bacias sanitárias.

Além dos ensaios previstos nas normas, a fim de caracterizar melhor o desempenho das bacias sanitárias, foi realizado o ensaio de transporte de pasta de soja, visando medir a quantidade de descargas necessárias para remover todas as mídias da tubulação de dezoito metros de comprimento. $\mathrm{O}$ ensaio de transporte de pasta de soja tem como objetivo analisar a capacidade de transporte de sólidos deformáveis, verificando o número de descargas necessárias para transportar onze mídias - sete mídias de pasta de soja (totalizando $350 \mathrm{~g}$ ) e quatro bolas de papel higiênico - ao longo de dezoito metros de tubulação, que simula o ramal de esgoto sanitário, com declividade de $1 \%$ e diâmetro de 100 mm (ver Figura 11). 
Esse ensaio foi realizado nas bacias sanitárias com caixa acoplada consideradas aptas nos ensaios eliminatórios anteriores. Optou-se por realizá-lo, também, nas bacias sanitárias com caixa acoplada que apresentaram resultados próximos ao limite normativo, para fins de estudo. O ensaio foi realizado em duas condições distintas: com as mídias de pasta de soja não encapsuladas (Figura 10) e encapsuladas (Figura 11). Entretanto, a análise com as mídias não encapsuladas não se mostrou adequada, já que elas se desfazem durante as descargas, não sendo possível verificar com precisão o momento da eliminação das mídias.

A Figura 12 apresenta os resultados do ensaio de transporte de pasta de soja.
As bacias sanitárias avaliadas precisaram de duas a seis descargas para remover as mídias da tubulação de dezoito metros. A bacia sanitária que apresentou o pior resultado nesse ensaio (precisou de seis descargas para remover as mídias da tubulação) também foi a bacia sanitária com o pior desempenho no ensaio de remoção de pasta de soja não encapsulada. Esse resultado indica a diferença no desempenho das bacias sanitárias com caixa acoplada de modelos e fabricantes diferentes, mostrando que bacias sanitárias com o mesmo volume de descarga podem apresentar resultados distintos.

Figura 10 - Mídias utilizadas nos ensaios de remoção e transporte de pasta de soja não encapsulada (quatro bolas de papel higiênico e sete mídias de pasta de soja não encapsulada)

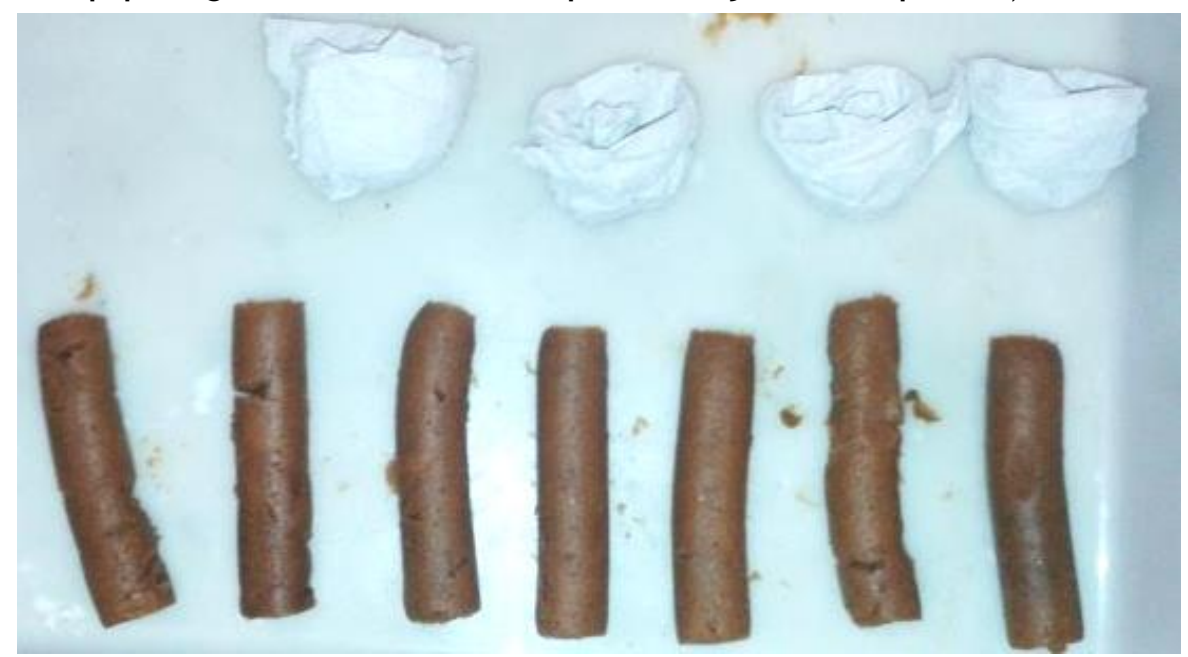

Figura 11 - Onze mídias do ensaio de remoção de pasta de soja encapsulada - sete mídias de pasta de soja (totalizando $350 \mathrm{~g}$ ) e quatro bolas de papel higiênico

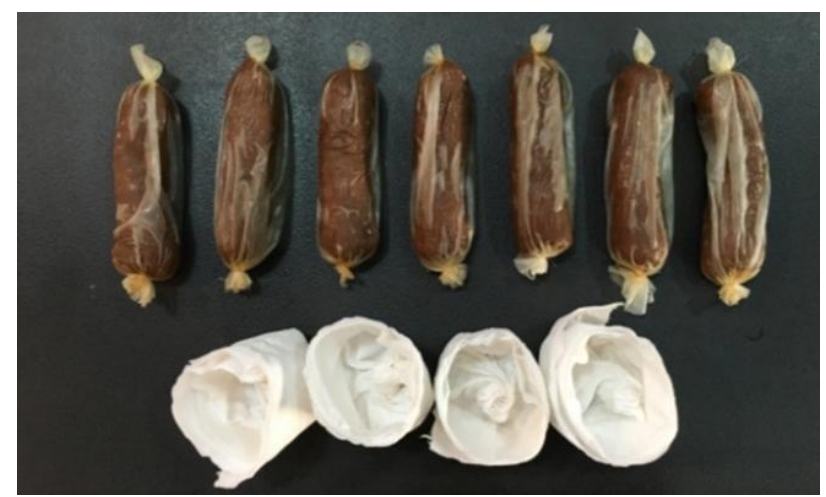

456 Valêncio, I. P.; Gonçalves, O. M. 
Figura 12 - Número de descargas necessárias para remover todas as mídias da tubulação
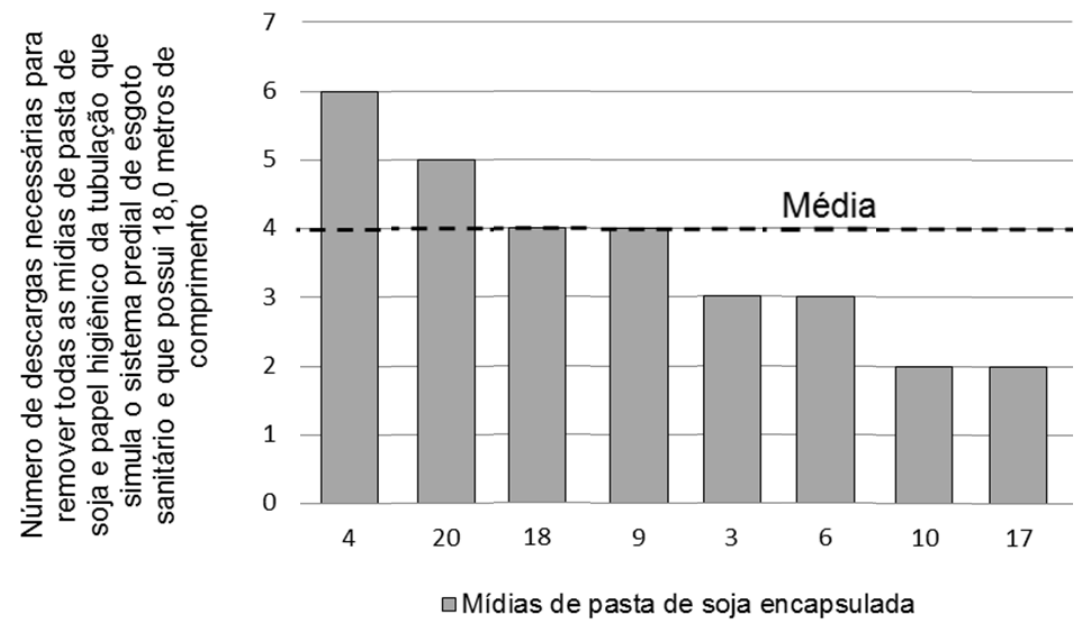

\section{Conclusões}

O estudo apresentado neste artigo focou na avaliação laboratorial do desempenho de bacias sanitárias com caixa acoplada e acionamento simples de 4,8 L/descarga, a fim de verificar a viabilidade de utilização destas. A substituição de bacias sanitárias com caixa acoplada de 6,8 L/descarga por bacias sanitárias com caixa acoplada de 4,8 L/descarga teoricamente reduz o consumo de água em dois litros a cada descarga. Entretanto, a redução do volume de descarga deve estar aliada ao desempenho do produto, pois, caso a bacia sanitária não apresente desempenho satisfatório para o usuário, este acionará duas ou mais vezes a descarga - e a redução não ocorrerá.

Foi observado que $95 \%$ das bacias sanitárias avaliadas atendem ao desempenho de remoção da própria bacia considerando os ensaios das normas brasileiras, o que mostra que a maioria dos produtos possui tecnologia suficiente para trabalhar com o volume reduzido. Entretanto, há também produtos que não atendem a requisitos mínimos das normas brasileiras, o que indica a necessidade de desenvolvimento do setor.

O maior problema verificado foi com relação ao desempenho do sistema de coleta de esgotos sanitários, pois $20 \%$ das bacias sanitárias foram reprovadas no ensaio de transporte de sólidos. A utilização de bacias sanitárias com volume reduzido sem o estudo aprofundado do efeito no sistema de esgoto pode causar transtornos à população como, por exemplo, o entupimento da rede de esgoto sanitário. Assim, ressalta-se a importância de se realizar, em estudos futuros, um aprofundamento na avaliação do transporte de sólidos ao longo do ramal predial, não apenas considerando o ensaio já constante na norma brasileira, mas também considerando o ensaio de transporte de sólidos deformáveis.

Com a realização dos ensaios foi possível verificar que a redução do volume consumido por descarga pode ser uma solução viável para reduzir o consumo de água potável nas condições atuais do sistema no Brasil (diâmetro de $100 \mathrm{~mm} \mathrm{e}$ declividade de $1 \%$ ), já que cinco bacias sanitárias foram aprovadas em todos os ensaios realizados. Entretanto, isso representa apenas $25 \%$ das bacias sanitárias avaliadas, o que indica a necessidade de melhoria no desenvolvimento das bacias sanitárias de 4,8 L/descarga.

\section{Referências}

AMERICAN SOCIETY OF MECHANICAL ENGINEERS. A112.19.2: ceramic plumbing fixtures. New York: ASME, 2013.

\section{ASSOCIAÇÃO BRASILEIRA DE NORMAS}

TÉCNICAS. NBR 15097-1: aparelhos sanitários de material cerâmico: parte 1: requisitos e métodos de ensaios. Rio de Janeiro, 2017.

\section{ASSOCIAÇÃO BRASILEIRA DE NORMAS} TÉCNICAS. NBR 15491: caixa de descarga para limpeza de bacias sanitárias: requisitos e métodos de ensaio. Rio de Janeiro, 2010.

BARRETO, D. Perfil do Consumo Residencial e Usos Finais da Água. Ambiente Construído, Porto Alegre, v. 8, n. 2, p. 23-40, abr./jun. 2008.

CÂMARA BRASILEIRA DA INDÚSTRIA DA CONSTRUÇÃO. Recursos Hídricos: propostas para habitação de interesse social. Brasília, 2016. 
CONSELHO BRASILEIRO DE CONSTRUÇÃO SUSTENTÁVEL. Aspectos da Construção Sustentável no Brasil e Promoção de Políticas Públicas: subsídios para a promoção da construção sustentável. Brasília, 2014.

GAULEY, B.; KOELLER, J. Evaluation of LowFlush-Volume Toilet Technologies to Carry Waste in Drainlines: a Canada MORTGAGE and housing corporation Project. Mississauga; Yorba Linda: Gauley and Koeller, 2005.

GHISI, E.; OLIVEIRA, S. M. Potential For Potable Water Savings by Combining the Use of Rainwater and Greywater in Houses in Southern Brazil. Building and Environment, v. 42, p. 1731-1742, 2007.

KOBAYASHI, N.; OTSUKA, M. A Study on Evaluation of a Super Water-Saving Toilet in Regard to the Drainage Performance Thereof in the House Drain Section. In: INTERNATIONAL SYMPOSIUM CIBW062 ON WATER SUPPLY AND DRAINAGE FOR BUILDINGS, 38., Edinburgh, 2012. Proceedings... Edinburgh, 2012.

OLIVEIRA, L. H. de. As Bacias Sanitárias e as Perdas de Água nos Edifícios. Ambiente Construído, Porto Alegre, v. 2, n. 4, p. 39-45, out./dez. 2002.

\section{PLUMBING EFFICIENCY RESEARCH \\ COALITION. The Drainline Transport of Solid}

Waste in Buildings. Nov. 2012. Disponível em: $<$ http://www.plumbingefficiencyresearchcoalition. org/wp-content/uploads/2012/12/Drainline-

Transport-Study-PhaseOne>.Acesso em: 25 jun. 2018.

\section{PLUMBING EFFICIENCY RESEARCH}

COALITION. The Drainline Transport of Solid Waste in Buildings: phase 2.0.2015. Disponível em:

$<$ http://www.plumbingefficiencyresearchcoalition. org/projects/drainline-transport-of-solid-waste-inbuildings/>. Acesso em: 25 jun. 2018.

\section{SILVA, G. S. da. Programas Permanentes de} Uso Racional da Água em Campi

Universitários: o Programa de Uso Racional da Água da Universidade de São Paulo. São Paulo, 2005. 482 f. Dissertação (Mestrado em Engenharia Civil) - Curso de Engenharia Civil, Escola Politécnica, Universidade de São Paulo, São Paulo, 2005.

VALENCIO, I. P.; GONCALVES, O. M. Field Evaluation of Water Consumption and Drainage System Performance When 6.8Lpf Toilets Were Replaced by 4.8Lpf Toilets. In: INTERNATIONAL SYMPOSIUM CIBW062 ON WATER SUPPLY AND DRAINAGE FOR BUILDINGS, 43., Haarlem, 2017. Proceedings... Sao Paulo: USP, 2017.

Isabella Pastore Valêncio

Departamento de Construção Civil, Escola Politécnica | Universidade de São Paulo | Av. Prof. Almeida Prado, Trav. 2, n. 83 | São Paulo SP - Brasil | CEP 05508-070 | Tel.: (11) 3091-5234 | E-mail: isabella.valencio@yahoo.com

Orestes Marraccini Gonçalves

Departamento de Construção Civil, Escola Politécnica | Universidade de São Paulo | E-mail: orestes.goncalves@usp.br

Revista Ambiente Construído

Associação Nacional de Tecnologia do Ambiente Construído

Av. Osvaldo Aranha, $99-3^{\circ}$ andar, Centro

Porto Alegre - RS - Brasil CEP 90035-190

Telefone: +55 (51) 3308-4084

Fax: +55 (51) 3308-4054

www.seer.ufrgs.br/ambienteconstruido

E-mail: ambienteconstruido@ufrgs.br 